\title{
"O DEPÓSITO ARMAZENOU 25MIL TONELADAS DE MILHO” - UM TIPO DE INVERSÃO LOCATIVA NO PB
}

\author{
Letícia Lucinda MEIRELLES (D) $\boldsymbol{\Delta}$ \\ Universidade Federal de Minas Gerais (UFMG) \\ Márcia CANÇADO (DD \\ Universidade Federal de Minas Gerais (UFMG)
}

Open access

\section{EDITORES}

- Miguel Oliveira, Jr. (UFAL)

- René Almeida (UFS)

\section{AVALIADORES}

- Pablo Ribeiro (UFSM)

- Luísa Godoy (UFVJM)

SOBRE OS AUTORES

- Letícia Lucinda Meirelles Conceptualização, Investigação,

Escrita - Análise e Edição.

- Márcia Cançado

Conceptualização, Supervisão.

DATAS

- Recebido: 10/08/2021

- Aceito: 29/10/2021

- Publicado: 09/12/2021

\section{COMO CITAR}

MEIRELLES, Letícia Lucinda; CANÇADO, Márcia (2021). "O depósito armazenou 25 mil toneladas de milho" - um tipo de inversão locativa no PB. Cadernos de Linguistica, v. 2, n. 4, e487.

\section{RESUMO}

Neste texto, apresentamos o registro do projeto de pesquisa que estamos desenvolvendo como parte do estágio de pós-doutorado da autora Letícia Lucinda Meirelles. O objeto de estudo deste projeto é um subtipo do fenômeno genericamente conhecido como inversão locativa. Esse é um fenômeno sintático-semântico, no qual um sintagma com função semântica de locativo passa a ocupar uma posição pré-verbal, como em sentenças do tipo "nesta casa entrou um ladrão". Em nossa pesquisa, investigamos a inversão locativa que ocorre com verbos bitransitivos do tipo "armazenar" ("o fazendeiro armazenou 25 mil toneladas de milho no depósito”/“o depósito armazenou 25mil toneladas de milho”), com o intuito de propor, através do arcabouço teórico-metodológico da Semântica Lexical, qual(is) a(s) propriedade(s) semântica(s) que permite(m) a ocorrência desse tipo de inversão.

\section{ABSTRACT}

In this paper, we present the registration of the research project, which is being developed as part of the postdoctoral internship of one of he author Letícia Lucinda Meirelles. The study object of this project is a subtype of the phenomenon generically known as locative inversion. This is a 
syntactic-semantic phenomenon, in which a phrase, with a semantic locative function, occupy the pre-verbal position, such as in the sentence nesta sala 'in this room'entrou 'entered' um ladrão 'a thief'. In our research, we investigate the locative inversion that occurs with armazenar 'store' type ditransitive verbs (o fazendeiro armazenou $25 \mathrm{mil}$ toneladas de milho no depósito 'the farmer stored 25,000 tons of corn in the warehouse'/ o depósito armazenou 25mil toneladas de milho 'the warehouse stored 25,000 tons of corn'), in order to propose, using the theoretical-methodological framework of Lexical Semantics, which semantic properties allow the realization of this type of inversion.

\section{PALAVRAS-CHAVE}

Semântica Lexical; Inversão Locativa; Classes Verbais; Alternâncias Verbais; Propriedades Semânticas.

\section{KEYWORDS}

Lexical Semantics; Locative Inversion; Verbal Classes; Verbal Alternations; Semantic Properties. 


\section{INTRODUÇÃO AO OBJETO DE ESTUDO}

A inversão locativa (BARBOSA, 1989; LEVIN 1993; NAGASE, 2007; PILATI, 2002; MUNHOZ; NAVES, 2011) é um fenômeno linguístico bastante amplo presente em línguas como o inglês, espanhol e português, que diz respeito a diversos tipos de sentenças, nos quais um sintagma locativo, seja argumento verbal ou não, passa a ocupar a posição pré-verbal. Vejamos alguns exemplos desse fenômeno no português brasileiro (PB):

(1) a. Um corpo não identificado apareceu junto da praia.

a'. Apareceu um corpo não identificado junto da praia.

b. Junto da praia apareceu um corpo não identificado.

(2) a. Os noivos sentaram naquelas cadeiras.

b. Naquelas cadeiras sentaram os noivos.

(3) a. Um ladrão entrou nessa casa.

a'. Entrou um ladrão nessa casa

b. (N)essa casa (já) entrou ladrão.

(4) a. O fazendeiro armazenou 25 mil toneladas de milho no depósito.

b. O depósito armazenou 25 mil toneladas de milho.

Embora esse fenômeno ocorra frequentemente com verbos inacusativos, como pode ser visto nos exemplos em (1) e (3), a inacusatividade não delimita a ocorrência da inversão locativa (LEVIN; RAPPAPORT HOVAV, 1995), como pode ser visto nas sentenças em (2) e (4). Nos exemplos em (1) e (3), temos os verbos "aparecer" e "entrar", que são classificados como verbos inacusativos de dois lugares (BARBOSA, 1989; NAGASE, 2007; PILATI, 2002; MUNHOZ; NAVES, 2011). Tal classificação fica evidente ao observarmos as sentenças em (a'), nas quais os dois argumentos aparecem em suas posições sintáticas de origem, pospostos aos verbos. Em (1b) e (3b), os argumentos locativos, "junto da praia" e "nesta casa", alçam para a posição pré-verbal. Nas sentenças em (2), o verbo "sentar", sintaticamente classificado como inergativo, permite que o adjunto locativo passe a ocupar a posição pré-verbal, como pode ser visto em (2b). Por fim, no exemplo em (4), temos o verbo "armazenar", que é classificado como bitransitivo (CANÇADO; GODOY; AMARAL, 2013, 2017; CANÇADO; AMARAL; MEIRELLES, 2017), uma vez que toma três argumentos para ter o seu sentido saturado: alguém (sujeito) que armazena algo (objeto 1) em algum lugar (objeto 2). $\mathrm{Na}$ frase em (4b), o argumento locativo passa a ocupar a posição pré-verbal, correspondendo, portanto, à inversão locativa. 
Contudo, embora as sentenças de (1) a (4) mostrem a ocorrência desse fenômeno, ao analisarmos mais atentamente, podemos perceber que há diferenças entre os tipos de ocorrências. Além dos diferentes tipos de verbos que podem realizar a inversão locativa, há uma diferença quanto à presença das preposições nas sentenças invertidas. Nos exemplos em (1b) e (2b), a preposição não pode ser apagada ("*a praia apareceu um corpo não identificado"; "*aquelas cadeiras sentaram os noivos"); no exemplo em (3b), ela é opcional ("nessa casa entrou ladrão"/ "essa casa entrou ladrão"); porém, na sentença em (4b), a preposição deve ser necessariamente omitida, senão a frase fica agramatical ("*no depósito armazenou 25 mil toneladas de milho)

Neste trabalho, propomos analisar o tipo de inversão locativa que ocorre com os verbos do tipo "armazenar". Nesses casos, a sentença invertida, com apagamento obrigatório da preposição, ocorre com verbos bitransitivos e caracteriza-se como uma alternância verbal (LEVIN 1993), uma vez que um dos argumentos verbais (o que desempenha o papel de Agente) é omitido para que o argumento locativo passe para a posição pré-verbal.

(5) a. Eu abriguei um cãozinho perdido na garagem lá de casa.

b. A garagem lá de casa abrigou um cãozinho perdido (durante a madrugada).

(6) a. Maria acomodou três pessoas neste quarto.

b. Este quarto acomodou (bem) três pessoas.

(7) a. A atendente hospedou o casal na suíte máster.

b. A suíte máster hospedou o casal (durante sua lua de mel).

Nossa análise será feita sob o arcabouço teórico-metodológico da Semântica Lexical, que parte do pressuposto de que são as propriedades semânticas dos itens verbais que determinam o seu comportamento sintático (PINKER, 1989; JACKENDOFF, 1990; LEVIN, 1993; LEVIN; RAPPAPORT HOVAV, 2005; CANÇADO; GODOY; AMARAL 2013, 2017; CANÇADO; AMARAL, 2016, CANÇADO; AMARAL; MEIRELLES, 2017).

\section{JUSTIFICATIVA, HIPÓTESE E OBJETIVOS}

Em sintaxe, a inversão locativa no PB é recorrentemente ligada ao fato de nossa língua estar se tornando uma língua de sujeito nulo parcial e ao fato de o PB ser uma língua de tópico-sujeito (BARBOSA, 1989; NAGASE, 2007; PILATI, 2002; GRAVINA, 2008; MUNHOZ; NAVES, 2011). Contudo, embora esse fenômeno seja bastante estudado sob o ponto de vista sintático, trabalhos que apresentam um viés semântico do tema são escassos, o que justifica a realização de nossa pesquisa. Além disso, como nosso objeto de estudo é uma alternância verbal canônica, envolvendo o apagamento de um dos argumentos de um 
verbo bitransitivo e o alçamento de outro argumento, acreditamos que esse tipo específico de inversão locativa não seja uma manifestação da perda do parâmetro pro-dropem nossa língua.

A necessidade de uma análise semântica fica ainda mais clara quando observamos que não é todo verbo bitransitivo com argumento locativo que permite a ocorrência da sentença invertida. Vejamos os seguintes exemplos:

(8) a. A menina colocou o livro na mesa.

b. *A mesa colocou o livro.

(9) a. O pai trancou a filha no quarto.

b. *O quarto trancou a filha.

Embora os verbos "colocar" e "trancar" sejam sintaticamente iguais aos verbos "abrigar", "armazenar", "acomodar" e "hospedar", os dois primeiros não permitem que o argumento com função locativa ocupe a posição pré-verbal.

Além disso, como nosso foco é a análise de sentenças em que um argumento verbal locativo passa a ocupar uma posição pré-verbal, nosso objeto de estudo pode ser caracterizado como um tipo de alternância verbal, assunto que é um dos temas principais dos estudos em Semântica Lexical.

Nossa hipótese é de que os verbos do tipo "armazenar" apresentam alguma propriedade semântica específica, que os diferencia dos verbos do tipo "colocar" e "trancar", e que permite a ocorrência dessa alternância, que é um subtipo do fenômeno amplamente conhecido como inversão locativa.

Com o intuito de verificarmos nossa hipótese, elencamos os seguintes objetivos: (i) coletar, através do banco de dados VerboWeb (CANÇADO; AMARAL; MEIRELLES, 2017), quais verbos bitransitivos com argumento locativo permitem a ocorrência da forma invertida das sentenças e quais não permitem; (ii) analisar as diferenças entre esses verbos e; (iii) propor qual propriedade semântica diferencia os verbos em questão, sendo ela a responsável pela participação dos verbos do tipo "armazenar" na alternância que estamos analisando.

\section{METODOLOGIA}

Como já mencionamos, nossa pesquisa seguirá o arcabouço teórico metodológico da Semântica Lexical. Os pesquisadores dessa área geralmente seguem os seguintes passosmetodológicos: (i) identificar classes verbais; (ii) identificar comportamentos sintáticos compartilhados pelos verbos de uma mesma classe; (iii) identificar componentes do significado lexical que influenciam a variação gramatical. 
Tendo esses passos em mente, após termos coletado, através do banco de dados VerboWeb, todos os verbos bitransitivos com argumento locativo e termos separado aqueles que permitem a ocorrência da forma invertida daqueles que não a permitem, aplicaremos uma série de testes que acreditamos nos possibilitar descobrir qual(is) a(s) propriedade(s) semântica(s) que licencia(m) a realização do tipo de inversão locativa que estamos analisando.

O primeiro teste consiste na aplicação de paráfrases para tentar extrair o conteúdo semântico que os verbos carregam. A princípio, podemos dizer que verbos como "armazenar" e "trancar" se assemelham por poderem ser parafraseados pela seguinte sentença: "x age, causando y ficar em um determinado estado em algum lugar" (CANÇADO; GODOY; AMARAL, 2013, 2017; CANÇADO; AMARAL; MEIRELLES, 2017), assim como também pode ser dito para o verbo "anexar":

(10) a. O fazendeiro armazenou 25 mil toneladas de milho no depósito. - tb.O fazendeiro age, causando 25 mil toneladas de milho ficarem armazenadas no depósito. ${ }^{1}$

(11) a. O pai trancou a filha no quarto. - - tb.O pai age, causando a filha ficar trancada no quarto.

(12) a. O estudante anexou o arquivo no/ao e-mail. Fłb.O estudante age, causando o arquivo ficar anexado no/ao e-mail.

Embora os três verbos apresentem o mesmo tipo de paráfrase, apenas "armazenar" e "anexar" permitem que o argumento locativo passe a ocupar a posição pré-verbal:

(13) O depósito armazenou 25 mil toneladas de milho.

(14) Este email anexou um arquivo zip que contém documentos maliciosos do MS Office. ${ }^{2}$

Contudo, apenas o argumento do verbo "armazenar" pode ser retomado por um sintagma que explicita sua função de locativo. Esse é um segundo teste que aplicaremos na tentativa de descobrir se os sujeitos em questão são realmente sintagmas locativos.

(15) [O depósito]i armazenou 25 mil toneladas de milho. Foi lái que elas ficaram guardadas até o dia da exportação.

(16) [O e-mail] anexou o arquivo (certinho). ??Foi lái que todas as informações ficaram salvas. 
A diferença dos exemplos em (15) e (16) pode ser um indício de que apenas o verbo "armazenar" faça a inversão locativa, enquanto a sentença com o verbo "anexar" pode ser outro tipo de alternância.

Então, novamente nos resta a pergunta: qual propriedade semântica específica verbos do tipo "armazenar" apresentam que os distinguem dos demais verbos bitransitivos com argumento locativo? Essa é a questão crucial a ser respondida em nosso trabalho e buscaremos respondê-la, fazendo uma análise semântica acurada do significado dos itens verbais em questão. Para tanto, utilizaremos testes sintático-semânticos como os que mostramos nesta subseção, além de outros testes que pretendemos propor durante a realização do trabalho.

\section{REFERENCIAL TEÓRICO}

Nosso trabalho insere-se na linha de pesquisa da Semântica Lexical, também conhecida como Interface Sintaxe-Semântica Lexical. Essa linha de pesquisa estuda como o significado dos itens lexicais, principalmente dos verbos, é estruturado, de modo que possa motivar a sua sintaxe. De acordo com Levin e Rappaport Hovav (2005), desde a década de 80, muitas teorias da gramática têm sido construídas baseadas no pressuposto de que a realização sintática dos argumentos verbais é motivada pela semântica do verbo (PINKER, 1989; LEVIN; RAPPAPORT HOVAV, 1995, 2005; WUNDERLICH, 2012; CANÇADO; GODOY; AMARAL, 2013, 2017; CANÇADO; AMARAL; MEIRELLES, 2017). Essas teorias são chamadas de teorias de projeção (LEVIN; RAPPAPORT HOVAV, 2005), pois assumem que a realização dos argumentos na sintaxe é uma projeção das propriedades lexicais dos verbos, que são de natureza semântica. Assim, o objetivo das teorias da Interface Sintaxe-Semântica Lexical que assumem essa hipótese é propor representações semânticas para os verbos que possam servir de base para a explicação de sua sintaxe.

Contudo, não é qualquer propriedade semântica que é relevante para a sintaxe. Grimshaw (2005), por exemplo, aponta que, apesar de o inglês possuir muitos verbos relacionados com a noção de cor (paint 'pintar', color 'colorir', bleach 'corar', redden 'avermelhar' e stain 'manchar') não há nada particular na realização de seus argumentos que faça com que eles possam ser agrupados em uma mesma classe verbal. Do mesmo modo, Pesetsky (1995) mostra que não há diferenças sintáticas entre verbos que denotam emissão de sons altos (bellow 'berrar', shout 'urrar') e verbos que denotam emissão de sons baixos (whisper 'sussurrar', murmur 'murmurar'). No entanto, segundo o autor, a distinção entre verbos que denotam a maneira de falar ("sussurrar", "murmurar", "berrar" e "urrar") e verbos que denotam um conteúdo de fala (say 'dizer', speak 'falar', propose 'propor') é relevante para a classificação dos verbos em classes verbais, uma vez que, no inglês, 
apenas os verbos do segundo tipo aceitam um complemento sentencial, como em Mary said that she is angry 'Mary falou que ela está furiosa', mas não *Mary whispered that she is angry 'Mary sussurrou que ela está furiosa'.

Seguindo a mesma linha de raciocínio, Godoy (2009) mostra que no PB há um agrupamento de verbos que acarretam a propriedade semântica "ter boca" para o argumento externo. São verbos como "beijar", "gritar", "beber", "bocejar", "falar" e "assoviar". No entanto, esses verbos não formam uma classe verbal, pois apresentam tanto comportamentos sintáticos distintos, quanto outras propriedades semânticas distintas. Por exemplo, apenas o verbo "beijar" ocorre na construção reflexiva ("Ana se beijou"). "Gritar", "bocejar" e "assoviar" são intransitivos ("Carolina gritou sem parar"/“Felipe bocejou durante a aula" / "Henrique assoviou durante todo o jogo"), enquanto "beber" e "beijar" são transitivos ("Ricardo bebeu um copo de leite"/ "Joana beijou Marcos"). Do ponto de vista aspectual, "assoviar", "gritar" e "bocejar" são verbos de atividade, enquanto "beber" é um verbo de accomplishment. ${ }^{3}$ Portanto, a autora conclui que "ter boca" não é uma propriedade semântica relevante para a classificação dos verbos.

Tendo em mente a informação de que não é toda propriedade semântica que tem impacto sobre a sintaxe verbal, em nossa pesquisa, procuramos descobrir qual a propriedade semântica responsável pelo licenciamento da ocorrência do subtipo de inversão locativa com os verbos do tipo "armazenar". Mais especificamente, nosso trabalho segue os moldes teórico-metodológicos empregados na construção do banco de dados e análises de verbos VerboWeb (CANÇADO; AMARAL; MEIRELLES, 2017), que serão explicitados a seguir.

\subsection{VERBOWEB: UM BANCO DE DADOS E ANÁLISES DO LÉXICO VERBAL DO PB}

O VerboWeb é um banco de dados fruto de uma extensa investigação do léxico verbal do PB, iniciada e coordenada pela Profa. Dra. Márcia Cançado, criadora do Núcleo de Pesquisa em Semântica Lexical (NuPeS) da Faculdade de Letras da Universidade Federal de Minas Gerais (UFMG). Tendo sido iniciado em 2017, atualmente o banco conta com mais de 1400 verbos, divididos em classes e subclasses.

A ideia do desenvolvimento do banco surgiu a partir do projeto "Catálogo de verbos do PB", também coordenado pela Profa. Dra. Márcia Cançado, que tem como principal objetivo catalogar os verbos do PB descrevendo suas propriedades sintáticas e semânticas. A análise de um primeiro grupo de verbos, chamado "verbos de mudança", já foi publicada

\footnotetext{
3 Verbos de accomplishment denotam situações que mudam ao longo do tempo e atingem um ponto final específico: "construir uma casa". Verbos de atividade, por outro lado, denotam situações homogêneas, durativas e que não atingem um ponto final: "correr por duas horas".
} 
como o livro "Catálogo de verbos do português brasileiro: verbos de mudança". Os verbos desse primeiro volume já se encontram no banco VerboWeb, com suas respectivas análises sintáticas e semânticas.

Vejamos o exemplo do verbo "quebrar" em uma sentença do tipo "a soprano quebrou a taça de cristal". De acordo com Cançado, Godoy e Amaral (2013, 2017), esse verbo pertence à classe dos verbos de mudança de estado opcionalmente volitivos. No banco de dados, encontramos as seguintes informações sobre o verbo "quebrar":

- Propriedades semânticas: (i) o verbo pertence à classe dos "verbos de mudança de estado opcionalmente volitivos"; (ii) essa classe denota que uma entidade passa a ficar em um determinado estado; os verbos dessa classe apresentam o aspecto lexical de accomplishment, os verbos dessa classe atribuem o papel temático de Causa ("⿺ grito da soprano quebrou a taça de cristal") ou Agente ("a soprano quebrou a taça de cristal") para o seu sujeito e de Paciente para o seu objeto. ${ }^{4}$

- Propriedades sintáticas decorrentes das propriedades semânticas: (i) o verbo licencia a forma incoativa por denotar mudança de estado ("a taça de crista (se) quebrou”); (ii) o verbo aceita a inserção do constituinte que denota causa em adjunção ("a taça de cristal (se) quebrou com o grito da soprano"); o verbo aceita a inserção de um instrumento, pois pode apresentar um sujeito agente ("a soprano quebrou a taça de cristal com um martelo"); o verbo apresenta a forma passiva, também devido à existência de um agente ("a taça de cristal foi quebrada pela soprano").

É importante mencionar que, como mostram Cançado, Amaral e Meirelles (2017, 2018), dentro de uma classe verbal podem haver subclasses compostas por verbos que se agrupam por propriedades semânticas e sintáticas mais específicas. Um exemplo no banco VerboWebé a subclasse dos "verbos com objeto recíproco", contida na classe dos verbos de mudança de estado opcionalmente volitivos. Verbos recíprocos são aqueles que exigem que um dos seus argumentos denote dois (ou mais) referentes no mundo (DIXON, 1992; SILONI, 2007; GODOY, 2009, 2010; BECHIR, 2016), como o verbo "afastar".

(17) O decorador afastou os móveis.

4 De acordo com Cançado e Amaral (2016), os papéis temáticos de Causa, Agente e Paciente podem ser definidos da seguinte maneira: Causa - desencadeador de uma ação, sem controle (o sol queimou a plantação); Agente desencadeador de uma ação, com controle (o motorista lavou o carro); Paciente - entidade que sofre o efeito de uma ação, havendo mudança de estado (o acidente machucou a Maria) (CANÇADO; AMARAL, 2016, p. 43). 
Por ter um argumento que denota dois ou mais referentes ("os móveis"), o verbo "afastar" apresenta um comportamento sintático específico: ele licencia a forma descontínua (GODOY, 2009, 2010) desse argumento.

(18) O decorador afastou um móvel do outro.

Contudo, embora denote o sentido de reciprocidade, o verbo "afastar" ainda pertence à classe dos verbos de mudança de estado opcionalmente volitivos, pois apresenta as mesmas propriedades dos demais verbos da classe: atribui o papel temático de Agente ou Causa para o seu argumento externo ("o decorador/ o tremor de terra afastou os móveis") e apresenta a forma incoativa com a adjunção do sintagma que expressa causa ("osmóveis se afastaram com o tremor de terra").

Portanto, Cançado, Amaral e Meirelles (2017, 2018) concluem que os verbos com o objeto recíproco são uma subclasse da classe dos verbos de mudança de estado opcionalmente volitivos. Assim, as subclasses apresentam propriedades semânticas mais específicas, como a reciprocidade, atreladas a propriedades sintáticas adicionais, como a forma descontínua do argumento que denota dois referentes.

Em nossa pesquisa, seguindo o sistema de classificação utilizado no banco VerboWeb, pretendemos verificar se os verbos do tipo "armazenar", por realizarem a inversão locativa, constituem uma subclasse dos verbos bitransitivos com argumento locativo.

\section{CONSIDERAÇÕES FINAIS}

Neste projeto de pesquisa, mostramos que existe um subtipo específico de inversão locativa no PB, que ocorre quando o argumento, com função locativa, de verbos bitransitivos passa a ocupar a posição pré-verbal. Nesse tipo de inversão locativa a preposição do argumento locativo deve ser necessariamente apagada.

Acreditamos que esse fenômeno possa ser bem explicado através do arcabouço teórico-metodológico da Semântica Lexical, uma vez que se trata de uma alternância verbal que ocorre com verbos que apresentam a mesma sintaxe, mas que provavelmente apresentam características semânticas distintas.

\section{AGRADECIMENTOS}

As autoras agradecem ao CNPq pelo suporte financeiro. 


\section{REFERÊNCIAS}

BARBOSA, P. Locative as subjects? Gathering some data from aquisition and parsing. Linguistics, 611, 1989.

BECHIR, T. Os verbos recíprocos intransitivos no português brasileiro. Monografia (Bacharelado em Estudos Linguísticos) - Faculdade de Letras, Universidade Federal de Minas Gerais (UFMG), 2016.

CANÇADO, M.; AMARAL, L. Introdução à Semântica Lexicat. Papéis Temáticos, aspecto lexial e decomposição de predicados. Editora Vozes, Petrópolis, RJ, 2016.

CANÇADO, M.; AMARAL, L.; MEIRELLES, L. e colaboradores. Banco de Dados Lexicais VerboWeb: classificação sintático-semântica dos verbos do portuguêsbrasileiro. UFMG. 2017. Disponível em: http://www.letras.ufmg.br/verboweb/

CANÇADO, M.; AMARAL, L.; MEIRELLES, L. VerboWeb: uma proposta de classificação verbal. Revista da Anpoll, n. 46, v. 1, 2018.

CANÇADO, M.; GODOY, L.; AMARAL, L. Catálogo de verbos do português brasileiro: classificação verbal segundo a decomposição de predicados. Vol I - Verbos de mudança. Belo Horizonte: Editora UFMG, 2013.

CANÇADO, M.; GODOY, L.; AMARAL, L. Catálogo de verbos do português brasileiro: classificação verbal segundo a decomposição de predicados. Vol I. Verbosde mudança, 2 ed. Edição Revisada Amazon. 2017.

CANN, R. Formal Semantics: An introduction. Cambridge: Cambridge University Press, 1993.

DIXON, R. M. W. A new approach to English grammar, on semantic principles. Oxford: Clarendon Press, 1992.

GODOY, L. Os verbos recíprocos no PB e a hipótese da determinação semântico lexical sobre a sintaxe. ALFA, v. 53, n. 1. 2009

GODOY, L. A Semântica da dupla realização argumental dos verbos recíprocos. Revista do GEL, v. 7, n. 1. 2010.

GRAVINA, A. P. A Natureza do Sujeito Nulo na Diacronia do PB: estudo de um corpus mineiro (1845 a 1950). Tese de Doutorado. Universidade Estadual de Campinas, Campinas, 2008.

GRIMSHAW, J. 2005 [1993]. Semantic Structure and Semantic Content in Lexical Representation. In Grimshaw, J. (ed.), Words and Structure. Stanford: CSLI Publications, p. 75-89, 2005.

JACKENDOFF, R. Semantic structures. Cambridge: MIT Press, 1990.

LEVIN, B. English Verb Classes and Alternations: A Preliminary Investigation.Chicago: University of Chicago Press, 1993.

LEVIN, B.; RAPPAPORT HOVAV, M. Unaccusativity: at the syntax lexical semantics interface. Cambridge: MIT Press, 1995.

LEVIN, B.; RAPPAPORT HOVAV, M. Argument Realization. Cambridge: Cambridge University Press, 2005.

MUNHOZ, A.; NAVES, R. Construções de tópico-sujeito: uma proposta em termos de estrutura argumental e transferência de traços de C. S/GNUM: Estud. Ling., Londrina, n. 15/1, 2012.

NAGASE, E. A inversão locativa no português brasileiro. Dissertação de mestrado. Faculdade de Filosofia, Letras e Ciências Humanas, Universidade de São Paulo (USP), 2007.

PESETSKY, D. Zero Syntax. Experiences and Cascades. Cambridge, MA: MIT Press, 1995.

PILATE, E. Sobre a ordem verbo-sujeito no português do Brasil. Dissertação de mestrado. Universidade de Brasília (UnB), 2002.

PINKER, S. Learnability and Cognition: The acquisition of argument structure.Cambridge: MIT Press, 1989. 
SILONI, T. The syntax of reciprocal verbs: an overview. In: KÖNIG, E.; GAST, V. (Eds.) Reciprocalsandreflexives: crosslinguisticsandtheoreticalexplorations. Berlin: Mouton de Gruyter, 2007.

WUNDERLICH, D. Lexical Decomposition in Grammar. In: WERNING, M.; HINZEN, W.; MACHERY, E. The Oxford Handbook of Compositionality. Oxford: Oxford University Press, p. 307-327, 2012. 